\title{
El poderoso influjo de la luna: intertextualidad en Cargamento de sueños, de Alfonso Sastre
}

\author{
Antonio Ballesteros González \\ UNED \\ aballesteros@flog.uned.es
}

Recibido: 13/11/2017

Aceptado: 23/10/2018

\section{RESUMEN:}

El presente artículo tiene por finalidad examinar los principales elementos intertextuales en Cargamento de sueños, pieza teatral breve compuesta por Alfonso Sastre (Madrid, 1926-), estrenada en 1948 y publicada un año después. El interés primordial y novedoso de este análisis radica en el estudio de los vínculos literarios con autores - principal, aunque no exclusivamente - de lengua inglesa, aspecto escasamente estudiado hasta la fecha en esta obra de Sastre, que también se examina a la luz de una producción relativamente reciente de la misma en el Teatro Español de Madrid (2016).

PALABRAS CLAVE: Alfonso Sastre, «Arte Nuevo», teatro de vanguardia, intertextualidad, José Luis Garci.

The Powerful Influence of the Moon: Intertextuality in Cargamento de sueños (Dream Cargo) by Alfonso Sastre

\section{ABSTRACT:}

This article aims at examining the most relevant intertextual elements in Cargamento de sueños (Dream Cargo), a short play by the Spanish playwright Alfonso Sas- 
tre (Madrid, 1926-), premiered in 1948 and published one year later. In this analysis attention is paid to the play's literary links with - mainly but not exclusively - English-speaking authors, an aspect which has been scarcely studied so far, together with a comparative analysis with a relatively recent production of the play in the "Teatro Español» in Madrid (2016).

KEY WORDS: Alfonso Sastre, "Arte Nuevo», avant-garde drama, intertextuality, José Luis Garci.

Pese a las relativamente escasas ocasiones en las que se representan sus obras dramáticas, Alfonso Sastre (Madrid, 1926-) es uno de los nombres ilustres e imprescindibles del teatro contemporáneo en lengua española desde que comenzara su prolífica carrera teatral en el marco referencial de la posguerra hasta llegar a nuestros días, como testimonian numerosos estudios dedicados a su producción para la escena, tanto en España como en el extranjero $^{1}$. A lo largo y ancho de una trayectoria literaria que abarca ya setenta años, Sastre ha demostrado ser no solo portavoz de las principales tendencias e inquietudes teatrales e intelectuales del siglo XX, como lo describiera Carolina Henríquez-Sanguineti (2001), sino que su impronta se extiende hasta nuestra contemporaneidad. Mientras redactaba estas líneas, se representaba en el Centro Dramático Nacional ${ }^{2}$, lugar en el que se estrenó por el Teatro Popular Universitario en 1953, en pleno periodo de represión franquista, la que fue la primera de sus piezas dramáticas más emblemáticas: Escuadra hacia la muerte, magistral y conmovedor alegato antibelicista, prohibido por la censura - némesis de las obras de Sastre, principalmente en la etapa de la dictaduratras unas pocas representaciones. No es azaroso que la acción de su primer estreno profesional, La mordaza (Teatro Reina Victoria, 1954), reflejara de manera simbólica una apología de la libertad

1 Véanse a tal efecto las bibliografías incluidas en las excelentes ediciones de La sangre y la ceniza y Crónicas romanas (1979) y, sobre todo, de La taberna fantástica y Tragedia fantástica de la gitana Celestina (2009), llevadas a cabo, respectivamente, por Magda Ruggeri Marchetti y Mariano de Paco.

2 Versión y dirección de Paco Azorín. Del 7 al 27 de octubre de 2016. 
de expresión. En sus propias palabras: «Vivimos amordazados. No somos felices. Este silencio nos agobia. Todo esto puede apuntar a un futuro sangriento» (en de Paco, 2009: 20).

Estas preocupaciones impregnan en general el conjunto de la obra de Alfonso Sastre, que presenta una evolución coherente con su ideario político y teatral, dos aspectos que han estado siempre imbricados y que se complementan en sus piezas dramáticas. Mariano de Paco (en Sastre, 2009: 18 y ss.) ha recogido las principales aproximaciones taxonómicas a la producción del autor, que podrían sintetizarse en una primera etapa de formación con énfasis en aspectos existenciales (comprendería las piezas en un acto concebidas para el proyecto de Arte Nuevo); una segunda en la que predominan los que Farris Anderson (1971) denomina dramas de posibilidad, en los que Sastre experimenta con la tragedia como género y en los que su escritura deriva desde los postulados metafísicos hacia los sociales (Muerte en el barrio, La cornada...), para desembocar en planteamientos revolucionarios (Guillermo Tell tiene los ojos tristes, En la red...). Son dramas en los que, pese a la telaraña existencial y política en la que se halla envuelto el ser humano, se subraya la capacidad de actuar contra un sistema injusto y opresivo, por mucho que dicha actividad volitiva se vea contrapesada inexorablemente por un destino acerbo; finalmente, una tercera fase de la obra de Sastre comprendería las que él mismo llamó tragedias complejas, en las que, partiendo de presupuestos decididamente realistas, el dramaturgo plantea obras teatrales de «agitación social» y de impulso revolucionario. En este último periodo, muy influido por la visión brechtiana de la tragedia, se insertan obras como La sangre y la ceniza, La taberna fantástica, Crónicas romanas y Los últimos días de Emmanuel Kant, entre muchas otras. Partiendo de esta breve contextualización, el presente artículo tiene por finalidad analizar los principales elementos intertextuales ${ }^{3}$ vinculados sobre

3 Se entiende por intertextualidad en el presente escrito la relación explícita o implícita que se establece entre dos o más textos con los que un determinado autor «dialoga». No sólo se refiere a la cita o la influencia expresa entre dichos textos, sino 
todo a la literatura escrita por autores de lengua inglesa en Cargamento de sueños, una pieza teatral breve compuesta por Alfonso Sastre en 1946, estrenada en 1948 y publicada un año después, con el propósito de analizar, siquiera sea brevemente, cómo este «Drama, para vagabundos, en un acto» contiene en embrión la semilla fecunda y las preocupaciones que Sastre vertería en el resto de su producción teatral.

La obra constituye uno de los exponentes más representativos de Arte Nuevo, un intento programático de modernizar el aletargado panorama escénico de la España de posguerra desde los presupuestos del teatro experimental en el que se implicaron, además del propio Sastre, otros dramaturgos y artífices teatrales como Medardo Fraile, Alfonso Paso, José Gordón, Carlos José Costas y Francisco Esbrí, quienes decidieron crear en $1945^{4}$ una tendencia escénica que, glosando a Alfonso Sastre, «incendiara las viejas salas» e imbuyera «fuego, pasión, inocencia, audacia, amor al teatro» en el público de aquellos tiempos difíciles (de Paco, 2008: 58). Precursor de los grupos de «teatro independiente» que se gestaron con posterioridad en la España franquista, Arte Nuevo pretendió insuflar un impulso renovador a la escena española de los años cuarenta, alejándose de los patrones imperantes en las astracanadas, vodeviles, espectáculos folclóricos, melodramas post-benaventinos y comedias burguesas al uso, partiendo de presupuestos vanguardistas en la línea del teatro experimental que proliferaba en los países europeos desde la mitad de la década de los cuarenta del siglo XX.

En este sentido, Cargamento de sueños es una pieza dramática que recoge, y en la que se perciben, elementos intertextuales

a la «capacidad» que estos tienen de establecer entre ellos una «polifonía» mediante la cual todo texto es absorción y transformación de otro(s). En este sentido, me acojo a las nociones y derivaciones interpretativas del término que pueden encontrarse en Mijail Bajtín (1979) y Julia Kristeva (1978). Puede consultarse una iluminadora explicación de la evolución del concepto en Ma Jesús Martínez Alfaro (1996).

4 En un encuentro en la cafetería madrileña «Arizona», hoy desaparecida, situada en la calle Alberto Aguilera. 
de variada procedencia, la mayoría de ellos en consonancia con la ideología implícita en los postulados existencialistas propugnados por autores francófonos como Jean Paul Sartre o Albert Camus, rastreados sobre todo en las primeras obras de Alfonso Sastre. La fascinación que el escritor español ha sentido siempre por algunos de los principales exponentes de la dramaturgia internacional se evidencia en una doble vertiente: por una parte, las versiones y traducciones acometidas, como en el caso, por ejemplo, de obras de Peter Weiss, Kafka, Eurípides, Pirandello, Strindberg, Ibsen, Büchner y Wilde; por la otra, en los paradigmas intertextuales de muy diversas fuentes literarias que se aglutinan en sus textos. Mi propósito en estas páginas radica en llevar a cabo un estudio incipiente, que no pretende ser exhaustivo por razones de espacio, de los vínculos literarios de Cargamento de sueños con autores de lengua inglesa de un teatro que quería ser «Una luz y un eco hacia la eternidad», frase que el por otra parte excelente crítico y director escénico Mariano de Paco, vindicador y perfecto conocedor del teatro de Sastre, atribuye erróneamente a Robert Browning (de Paco 2008: 59); en realidad, se trata de una traducción del verso que finaliza la primera estrofa de Adonais, el poema que Percy Bysshe Shelley dedicara a John Keats, una de las más célebres elegías de todos los tiempos. Creo que la precisión, además de académicamente justa, resulta significativa, pues implica una elección que considero motivada por parte de los miembros de Arte Nuevo -o por Sastre al menos-, dado el contexto en el que Shelley escribe Adonais, poema que refleja a Keats como el chivo expiatorio de una sociedad lerda y cruel que maltrata a sus poetas más excelsos:

I weep for Adonais - he is dead!

Oh, weep for Adonais! though our tears

Thaw not the frost which binds so dear a head!

And thou, sad Hour, selected from all years

To mourn our loss, rouse thy obscure compeers,

And teach them thine own sorrow, say: «With me 
Died Adonais; till the Future dares

Forget the Past, his fate and fame shall be

An echo and a light unto eternity!» (Shelley 2003: 531).

Ese eco y esa luz hacia la eternidad convirtieron a John Keats en el epítome del artista joven que, como los propios componentes de Arte Nuevo, luchó por abrirse camino en un mundo hostil a la literatura y el arte. Los jóvenes dramaturgos, que durante dos años intentaron sacar adelante su ambicioso proyecto escénico, al que luego le seguirían otros liderados por Sastre, como el Teatro de Acción Social (TAS; 1950) y el Grupo de Teatro Realista GTR; 1960), relegados de los escenarios de los teatros profesionales como el Infanta Beatriz y el Lara, y condenados a vagar por los salones de actos de los Institutos de Enseñanza Media (Cargamento de sueños se representaría en el Ramiro de Maeztu), podrían haberse mirado en el modelo de Keats. La hiperbólica comparación, cabe admitirlo, llevaría consigo no pocas dosis de idealismo, teniendo en cuenta además que la crítica teatral de la época no les fue en absoluto adversa (de Paco 1987-88-89). Pero precisamente de lo que no carecían Sastre y los demás miembros del grupo era de un arrebatador entusiasmo, pues no en vano iban en pos de «la renovación total del teatro»" En el «Poema de un Teatro de Vanguardia» de Alfonso Sastre, hoy perdido, recitado ante el público el 15 de noviembre de 1947, se podían leer los versos siguientes:

Venimos al asalto de un viejo edificio,

de una vieja cloaca.

$[\ldots]$

¡Traemos la gran idea, la encendida idea

de una vida mejor,

de un arte nuevo!

[...]

5 En palabras de José María de Quinto (en de Paco, 1987-88-89: 1067). 
No somos la vieja gente de teatro que nos viene diaria, petrificada ya en la cartelera.

¡Somos la nueva gente del teatro! (de Paco, 1987-88-89: 1074).

El autor ya se hallaba familiarizado por aquel entonces con el teatro vanguardista francés y norteamericano. En la presentación de Arte Nuevo en la sala Infanta Beatriz el 31 de enero de 1946, se repartieron unas cuartillas impresas en las que se defendía que «Nuestro vanguardismo no es un 'ismo' más. Es la forma que imponen hoy Eugene O'Neil (sic) en Norteamérica y Noel Conard (sic, por Noël Coward) en Inglaterra» (en de Paco, 1987-88-89: 1068), lo que subraya la proyección «internacional» de un proyecto teatral decidido a cambiar los patrones caducos de la escena española de la posguerra, si bien la alusión a Coward, vista desde una perspectiva actual, resulta un tanto extraña, dada su adscripción a un teatro de «alta comedia»y, por tanto, de índole claramente tradicional y burgués.

En definitiva, «Ewigkeit» («eternidad» en alemán) es precisamente el vocablo que domina el escenario de Cargamento de sueños, en una acción dramática que se desarrolla, simbólicamente, «en una encrucijada cualquiera del viejo continente europeo», enclave en el que dos vagabundos indagan en el sentido de la existencia, en el profundo sentimiento de soledad del ser humano, en el sufrimiento causado por el recuerdo y el olvido, en la violencia inherente a nuestra especie, en la vacilación entre el sueño y la vigilia, aspectos que nos recuerdan invariablemente a Esperando a Godot de Beckett, a la que la obra de Sastre precedió en el tiempo. La problemática existencial inherente a ambas piezas dramáticas reflejaba el denominador común ideológico de unos autores profundamente conmocionados por la realidad cruel de una Europa devastada por espantosas contiendas bélicas y la alargada sombra de la «Guerra Fría». La valoración de Esperando a Godot ${ }^{6}$ por par-

6 Escrita en francés por Beckett en 1948, estrenada en 1953 en el parisino Théâtre de Babylone, y representada por primera vez en España en la Facultad de Filosofía y Letras (hoy Edificio A de Filología) por «Dido Pequeño Teatro» el 28 de marzo 
te de Sastre, que redactó un perceptivo estudio de la tragicomedia beckettiana en el número 1 de la revista Primer Acto en 1957, donde por primera vez se publicó la obra en español, comienza con una empatía inicial, reconociendo que la trama de Esperando a Godot no es ni más ni menos que el argumento de nuestra propia existencia, la tragedia de la espera, de la salvación que nunca llega (Sastre, 1957). Como acertadamente afirma Farris Anderson, "One senses that Sastre was profoundly and irrevocably impressed by Waiting for Godot, and that this essay of 1957 was the result of that play's initial impact on him» (1971: 45). Sin embargo, como el mismo crítico analiza con agudeza, la reacción posterior de Sastre con respecto a la tragicomedia beckettiana desde 1957 hasta 1965, cuando publica «Anatomía del realismo», distó de ser tan empática, consecuencia de la propia evolución personal y artística del dramaturgo madrileño, que mantendría con respecto a la pieza dramática del genial escritor dublinés una postura ambivalente, llegando a señalar de modo tajante que le hubiera horrorizado ser el autor de Esperando a Godot ${ }^{7}$. De acuerdo con Anderson, dado que el énfasis principal de la vida intelectual de Sastre ha sido una lucha sostenida contra el nihilismo, su visión de la obra se fue transformando paulatinamente:

He admires and is moved by Beckett's play because it confirms his own propensity to view man in terms of his existential predicament, but his resistance to its nihilistic temptations parallels the other major dimension of Sastre's thought: the necessity to transcend the existential condition via meaningful action (1971: 45-46).

En su visión dialéctica de la vida, Sastre entiende que su teatro, como el de Brecht, se inserta dentro de la Historia, mientras

de 1955 (Rodríguez-Gago, 1987). No en 1956, como señala erróneamente Anderson (1971: 44).

7 En una entrevista personal con Farris Anderson el 29 de diciembre de 1964 (Anderson, 1971: 45). 
que el de Beckett es ajeno al devenir histórico. En cualquier caso, y pese a su controversia interna, que en no pocas ocasiones raya en la paradoja, Sastre siempre ha expresado su admiración por Beckett y por Esperando a Godot, que él entendió como un drama plenamente realista en sus postulados existenciales, y con el que comparte el uso del silencio presente en su teatro de carácter políglota y universal como elemento esencial y consustancial a lo dramático. Cargamento de sueños, en su énfasis existencial, en su poética del olvido y la vacilación entre lo onírico y lo «real», comparte importantes rasgos ideológicos y temáticos con la gran obra beckettiana, siendo uno de los más evidentes el reflejo de la tragedia de la sempiterna espera del ser humano y el drama de la salvación, patente en ambas piezas, lo que se plasma en las alusiones religiosas contenidas en ellas, en ocasiones trastocadas y subvertidas en su significado textual: «Oh, Padre nuestro: danos el pan de cada día para no reventar de aburrimiento» (155); «En verdad, en verdad, te digo que esta noche no has estado solo, Manfred» (158).

Cuando escribe Cargamento de sueños, Sastre se halla sumido en una crisis espiritual que deja una profunda huella en la obra, en la que abundan ecos cristianos, comenzando por el propio personaje de Jeschoua, que podría ser el trasunto de un sacerdote o del propio Cristo. Cuando se publicó por primera vez en 1949, la obra iba precedida de la dedicatoria «A los vagabundos. Porque en un instante cualquier de esta noche oirán de los labios metafísicos del Cristo el anuncio de la madrugada». Posteriormente, Sastre prescindió de la oración causal y dejó tan sólo la leyenda «Drama para vagabundos». La acción dramática de la obra, en la que late de manera inequívocamente hamletiana la tentación del suicidio, abortada por «la angustia de un más allá que permanece indescifrable: una caída en el vacío...» (153), se concibe como un acto confesional en el que Man (nombre simbólico y significativo, como todos los de la obra), el febril vagabundo que lleva sobre sus espaldas un «cargamento de sueños», representando así a toda la humanidad, relata su 
vida a Jeschoua, acaso su conciencia y, por lo tanto, su doble. Mariano de Paco (2008: 59-60) ha incidido acertadamente en el sustrato calderoniano de la obra, que no es otra cosa que un auto sacramental de carácter simbólico y vanguardista, como el propio Sastre reconoció. Man es el «Everyman» de la «morality play» homónima, el epítome de la humanidad que sufre, camina y espera, si bien en el caso de Cargamento de sueños, y por contraste con las obras de Calderón o del anónimo autor medieval inglés, la expectativa de un consuelo final dista de ser satisfactoria, permaneciendo en un espacio de ambigüedad tras una partida de ajedrez entre Man y la muerte que recuerda la que tiene lugar en El séptimo sello de Ingmar Bergman (1957), película que es asimismo fruto de las inquietudes y zozobras de una Europa sumida en las incertidumbres existenciales de la posguerra, contexto al que Sastre alude explícitamente en su obra: «Y sentir a Europa dentro de una vieja canción... Somos antiguos, Frau... Esa es toda nuestra profundidad. Sin embargo, hay alguien en Europa que espera... Algunos hombres...» (154). Pero Europa es para Sastre un ámbito en el que ya no hay lugar para la felicidad, convirtiéndose en el marco geográfico y simbólico en el que, significativamente, fracasa la relación de amor entre Man y Frau: «Nos fuimos a París. Yo quería que Frau experimentara la emoción europea. Pero allí la suerte nos fue poco propicia. Faltó el dinero y sufrimos privaciones. Una noche ella desapareció» (155). Por otra parte, en el personaje de Manfred laten las preocupaciones existenciales del personaje homónimo del drama metafísico del mismo título escrito por Lord Byron en 1816-18178 . La proyección onírica y el énfasis en los elementos religiosos de la pieza del escritor romántico inglés no son ajenos a la problemática de la obra de Sastre.

Por otra parte, como en los autos sacramentales, Esperando a Godot y El séptimo sello, en Cargamento de sueños son de gran importancia los elementos metadramáticos. La obra de Sastre co-

8 Debo, y agradezco, esta sugerencia a un perceptivo evaluador anónimo del presente artículo para Archivum. 
mienza con Man fijando su mirada desconsolada hacia el público, al que interpela de manera directa:

MAN. - Bueno, vamos a ver. ¿A qué habéis venido aquí? (Sarcástico). Me gustaría saberlo. (Con voz aburrida). Resulta curioso pensar que ni vosotros mismos lo sabéis (147)9.

Y posteriormente, cuando aparece en escena Jeschoua, el atribulado personaje señala, mirando al público con inquietud: «Hay muchos que me miran» (148). Pese a que su interlocutor insiste en que están completamente solos, Man sentencia: «Es como si la humanidad entera me contemplara esta noche» (148). Sastre admite haber basado este recurso en la influencia de Our Town, de Thornton Wilder (1938) (de Paco, 2008: 59), paradigma manifiesto de intertextualidad con el que comparte asimismo el énfasis en el devenir de las vidas, el transcurso del tiempo y la inexorable inmanencia de la muerte, si bien donde Wilder refleja estos procesos de manera 'natural' y no traumática, a la vez que teatraliza la presencia de los muertos en la remembranza de los vivos, Sastre desarrolla el drama en la acronía y la espectral irresolución ante lo que sucede más allá de la muerte, preocupación que Byron había resuelto en Manfred con tintes desafiantes y nihilistas. Como en Esperando a Godot y la práctica totalidad de las obras beckettianas, frente a la estética del recuerdo planteada por Wilder, Sastre insiste en la poética de la desmemoria, pese a que, aunque no se acuerda de lo inmediato, Man evoca de manera fidedigna un hecho traumático de su existencia, como es el asesinato de Frau (de nuevo un nombre representativo), la mujer a la que amó y que le traicionó, presente también en escena. Contar su vida a Jeschoua ${ }^{10}$, con el acontecimiento central del crimen

9 Todas las citas de la obra se refieren al texto incluido en Sastre (1964).

10 La obra despliega el uso de la técnica de mise en abyme aplicada a la narración de vidas que se engastan en el relato de Man. Así sucede con las de sus padres y la de Frau. 
cometido, supone sin duda para Man una suerte de expiación. En cualquier caso, dada la atmósfera onírica en la que se desenvuelve la acción dramática, todo podría ser un sueño.

En última instancia, Cargamento de sueños es un drama simbolista en la mejor tradición del género, en la línea, por ejemplo, de El hombre deshabitado de Rafael Alberti (1931), también compuesta a modo de auto sacramental de tintes vanguardistas. Y es en esta dimensión simbólica donde destaca en la obra de Sastre una influencia fundamental de carácter intertextual, que no es otra que la de Oscar Wilde, cuyas obras traduciría Alfonso Sastre junto a su hermano José para la editorial madrileña Edaf en la colección «Obras inmortales», publicada en $1961^{11}$. Esta analogía, que se me antoja crucial, no ha sido destacada por la crítica hasta la fecha. Desconozco hasta qué punto estaría el dramaturgo familiarizado a los veinte años con los escritos del célebre ingenio irlandés, pero sí se deduce claramente de Cargamento de sueños que conocía en profundidad algunos de sus textos más significativos. Por ejemplo, la utilización de esfinges, elemento tan querido a Wilde como objeto semiótico, en el escenario así lo indica. En la didascalia con la que se abre la obrita se especifica: «Una encrucijada. Al fondo, la llanura, sembrada de irreales - o sobrerreales ${ }^{12}$-esfinges» (147). Y más adelante, en palabras de Man:

Hay algo que se interpone entre mí y la verdad. Una carga querida y absurda. El estúpido soporte de los sueños. Y, por otra parte, acaso yo sea un sueño, una pasión sin objeto, un error del espacio. Las cosas viven ignorándome. No existo para ellas. Ellas tampoco existen. Nadie las ve. Esfinges..., ¡oh, sí! Esfinges espantosamente plácidas en su muerte. Y esto soy yo: algo detrás de una másca-

11 He editado parcialmente la traducción de los hermanos Sastre en diversos volúmenes de la editorial Edaf: Un marido ideal y Una mujer sin importancia (1997), El fantasma de Canterville y otros cuentos (2000) y La narrativa de Oscar Wilde (2016).

12 Obsérvese el carácter surrealista con el que Sastre dota a las esfinges. 
ra, algo detrás de una equivocación biológica [...]. Me llevo encima como un traje, un viejo, roto y querido traje. Eso es mi cuerpo (150).

Esfinges... y la verdad de las máscaras. Y el lirismo intenso - perceptible sobre todo en esta primera etapa de la producción literaria de Sastre - de algunas frases de tintes simbolistas y surrealistas que podrían imitar el lenguaje de Wilde: «Este cofre de sueños ilustrados, de tristes margaritas, de cadáveres» (150); «La luna, allá, y nosotros aquí, bajo un peso de sueños» (151); «Mis ojos se quedaron allá, en mi armario de luna. Se quedaron dentro como arañas. Me he venido sin ellos» (158). La luna, presente a lo largo de esa noche oscura del alma durante la que se desarrolla la mayor parte de la acción de Cargamento de sueños, ese satélite polisémico y cautivador que también ilumina la escena de Esperando a Godot, y que se torna testigo estridentemente silencioso de lo que acontece en la escena, como sucede en la Salomé de Wilde, donde también se nos habla de una historia de asesinato por amor y ambigua expiación.

Mas es precisamente en ese suceso, en ese crimen, cometido y emplazado, acaso de manera motivada por parte de Sastre, en «Whitchapel» (sic), con las inevitables reminiscencias de Jack el Destripador, donde se revela la influencia textual de Wilde y su «The Ballad of Reading Gaol»: «Se cumplió una vez más lo que dijo un infeliz..., un pobre infeliz: 'En la vida todos matan lo que aman'» (157). Se trata de la transliteración del verso «Each man kills the thing he loves», reiterado en las estrofas wildeanas. Con la angustia y remordimiento de haber asesinado a Frau se ve lastrado Man en su onírica carga de humanidad.

Cargamento de sueños fue llevada de nuevo a escena en tiempos más recientes (del 18 de febrero al 27 de marzo de 2016) en el Teatro Español, bajo la dirección de José Luis Garci, en compañía de El hermano, de Medardo Fraile. Anteriormente (en enero de 1990) había sido representada en el Centro Cultural de la Villa de Madrid, junto con otras piezas dramáticas en un acto de los principales artífices de la escritura dramática española del siglo XX, como 
Buero Vallejo, Carlos Muñiz, Lauro Olmo, Francisco Nieva, José Ma Rodríguez Méndez, Fernando Arrabal, José Martín Recuerda e Ignacio Amestoy ${ }^{13}$. La versión de José Luis Garci merece ser tenida en cuenta desde la perspectiva de un análisis intertextual, puesto que resulta especialmente significativa en términos teatrales al introducir innovaciones textuales y semióticas relevantes en varios niveles que la relacionan con el texto original de Sastre.

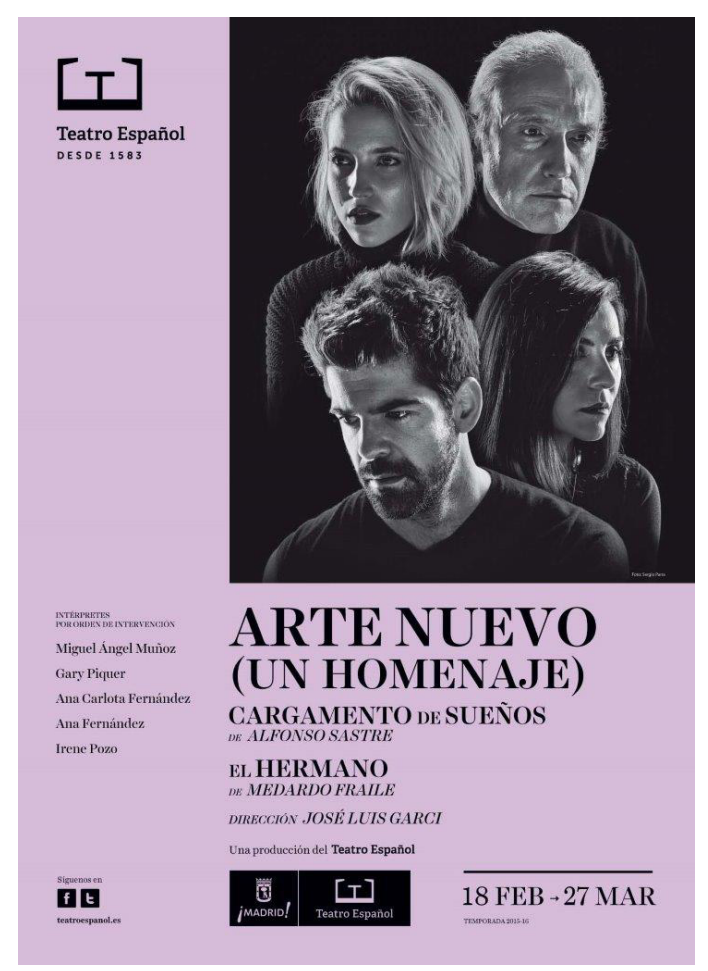

Cartel de Cargamento de sueños. Teatro Español de Madrid, 2016.

13 Noticia recogida en De Paco (en Sastre, 2009: 14, nota 16). Las obras se pusieron en escena dentro de un Ciclo de Dramaturgia Española Moderna y Contemporánea. 
Recibida por lo general con tibieza o con manifiesta animadversión por la crítica teatral ${ }^{14}$, la versión del cineasta español, pese a señalar que ha sido fiel al texto de Sastre, introduce modificaciones relevantes, a tenor de lo que se pudo ver en una puesta en escena magistral y cuidada desde un punto de vista dramático, destacando la escenografía y la iluminación. Resulta cuanto menos curiosa y paradójica la siguiente respuesta del conocido director a la pregunta de si ha sido muy fiel a los textos:

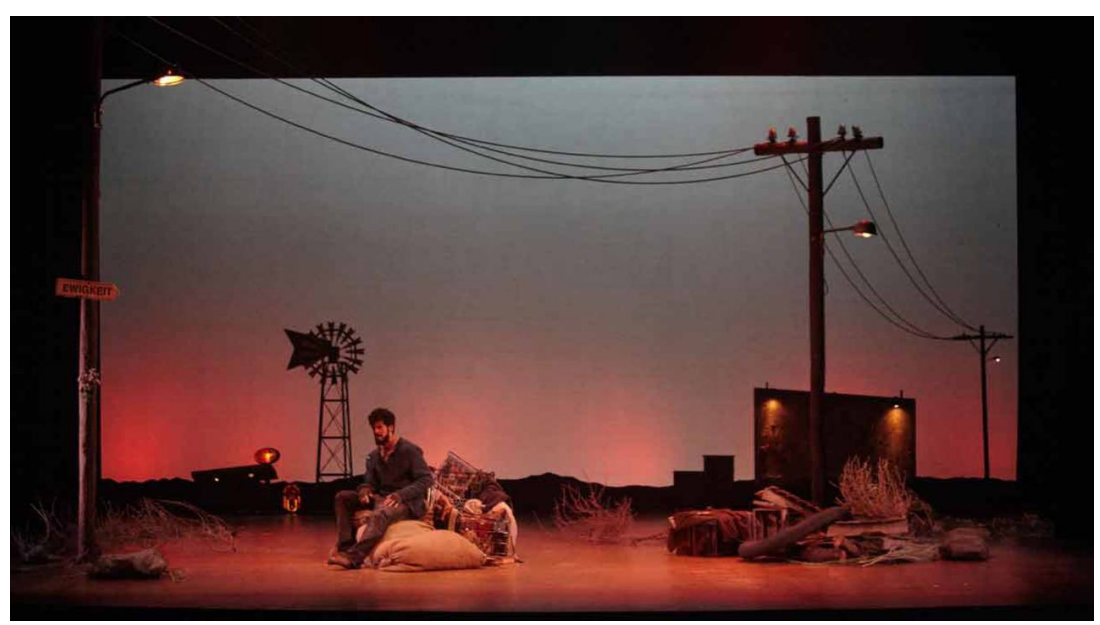

Decorado de Cargamento de sueños, Teatro Español, 2016.

Sí. Totalmente. Aparte de algún mínimo retoque lingüístico para que hoy se entienda mejor, o de quitar alguna ingenuidad - no olvidemos que los autores eran bastante jóvenes cuando escribieron estas obras-, he sido muy respetuoso. Pienso que hoy

14 En los siguientes enlaces pueden consultarse a modo de ejemplo algunas reseñas del espectáculo: Aldara Pérez. RTVE. (4/3/2016): http://www.rtve.es/noticias/20160304/arte-nuevo-garci-debuta-tablas-homenaje-teatro-posguerra/1308440. shtml; Ignacio Suárez-Zuloaga. España fascinante (blog): http://espanafascinante. com/arte-nuevo-un-homenajel-teatro-espanol-madrid/; José Catalán Deus. Periodista Digital (19/2/2016): http://www.periodistadigital.com/guiacultural/ocio-y-cultura/2016/02/19/arte-nuevo-y-peculiar-homenaje-critica.shtml 
en día en el asunto de las «adaptaciones» o «actualizaciones» en el teatro y también en la ópera, existe tanta manga ancha que dan ganas de decirle al director de algunos espectáculos que mejor habría sido que él mismo hubiera escrito otra obra para expresar lo que deseaba. No me gusta esa manga ancha ${ }^{15}$.

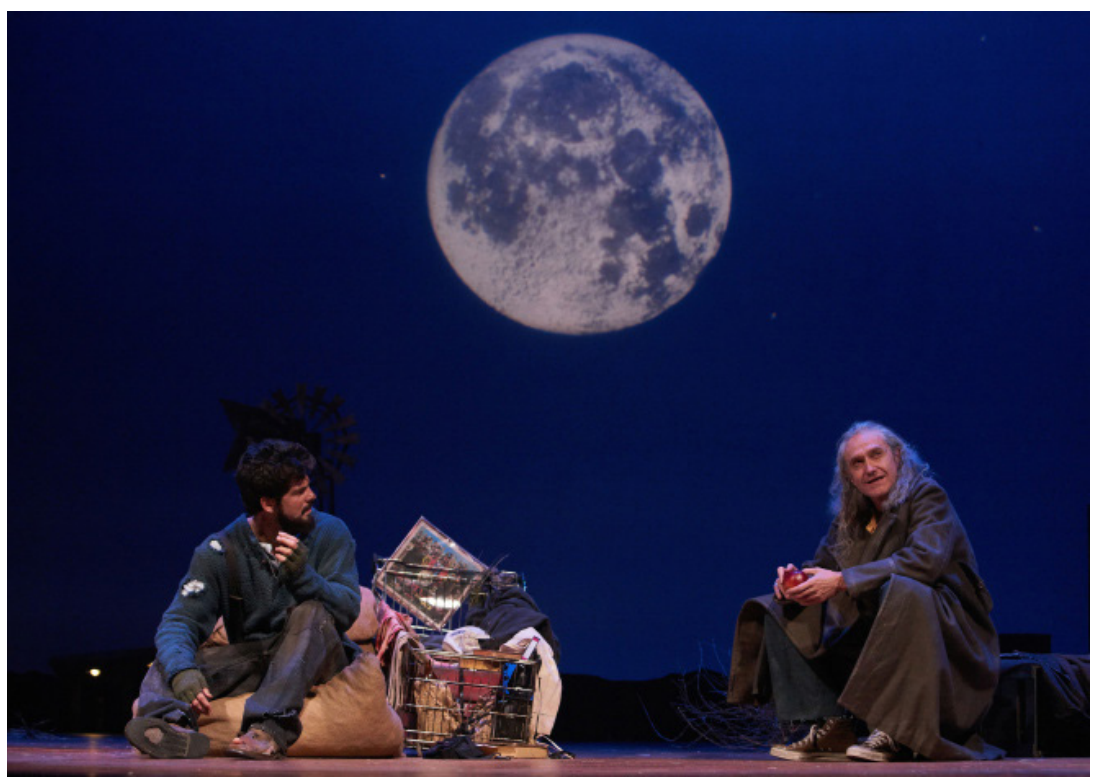

Escena de Cargamento de sueños. Madrid, Teatro Español, 2016.

Sin embargo, tal y como he apuntado, Garci introdujo novedades significativas en su versión escénica de la obra de Sastre: prescindió de las esfinges, del velador de espiritistas y hasta de los espiritistas mismos, además de eliminar otros personajes, como los padres de Man y los dos Hombres Indiferentes que

15 Carmen R. Santos. Entrevista a José Luis Garci. ABC (13/2/2016):

http://www.abc.es/cultura/teatros/abci-jose-luis-garci-no-gusta-manga-anchatienen-muchas-actualizaciones-teatrales-201602131204_noticia.html. 
aparecen puntualmente en dos ocasiones, al principio y al final de la obra, como indicadores de una sociedad que desprecia a los marginados. Todo ello no impedía la, desde mi punto de vista, elevada calidad de la versión del cineasta español. Destacaba la ensoñadora puesta en escena, plena de magia teatral, de hondo lirismo, que subrayaba la admiración que el director siente por una obra preterida y que consideraba de justicia reivindicar. A mi entender, la influencia de Esperando a Godot y el universo beckettiano era bastante evidente, con la larga peluca del personaje de Jeschoua, semejante, por ejemplo, a las que portan algunos personajes de la etapa minimalista última del escritor irlandés, como los de A Piece of Monologue (1979) o Ohio Impromptu (1981). De igual manera, alcanzaba una especial relevancia semiótica la presencia de una luna que se acrecentaba gradualmente hasta adquirir dimensiones gigantescas.

Con todo, la principal modificación textual de la pieza dramática de Sastre concierne al final de la obra, pues, frente a la conclusión desalentadora y nihilista del texto original, en el que, a la manera del Manfred de Byron, no se ofrece explícitamente un rayo de esperanza tras la partida de ajedrez con la muerte, Garci introduce de nuevo al personaje de Frau, con el que Man se reencuentra tras - suponemos - la muerte o la pesadilla. Evidentemente, la licencia transforma por completo una parte significativa del sentido de la obra.

Sea como fuere, el montaje de José Luis Garci, aparte de sus innegables valores estéticos intrínsecos, vino a servir de homenaje a unas obras precursoras urdidas en una época adversa por jóvenes entusiastas del hecho escénico que sirvieron para insuflar aire renovado a la opresiva situación en la que se hallaba el teatro de la posguerra. En el caso concreto de Alfonso Sastre, la experiencia de Arte Nuevo contribuyó a la forja de un dramaturgo magnífico, prolífico y proteico. En Cargamento de sueños, la que sin duda fue su primera obra teatral importante, se percibe la semilla de grandeza que luego fructificaría en una trayectoria dramatúrgica vasta y fecunda. 


\section{Referencias bibliográficas:}

Alberti, Rafael (2013) Noche de guerra en el Museo del Prado y El hombre deshabitado, Madrid, Biblioteca Nueva, 1931.

Alvarado, Esther (2016) «Entrevista a Alfonso Sastre». El Mundo, 17 de febrero. http://www.elmundo.es/cultura/2016/02/ 17/56c36b5b46163fbd3c8b4590.html

Anderson, Farris (1971) Alfonso Sastre, Nueva York, Twayne.

Bajtín, Mijail (1979) Estética de la creación verbal, México, Siglo XXI.

Beckett, Samuel (2012) En attendant Godot, París, Minuit, 1952 (version en inglés traducida por el propio Beckett: Waiting for Godot, Londres, Faber \& Faber, 1956).

Bergmann, Ingmar (2007) El séptimo sello, Vértice Cine, 1957.

Byron, George Gordon, Lord (1970) Manfred, en Poetical Works, Oxford, OUP, 1816-1817, pp. 390-406.

de Paco, Mariano (2008) «Camino hacia la eternidad: Cargamento de sueños y 'Arte Nuevo'». Prólogo a Cargamento de sueños, Alicante, Biblioteca virtual Miguel de Cervantes, pp. 57-61. http://biblioteca.org.ar/libros/200293.pdf

de Paco, Mariano (1993) «Alfonso Sastre y 'Arte Nuevo'», en de Paco, Mariano, Alfonso Sastre, Murcia, Universidad de Murcia, pp. 129-140.

de Paco, Mariano (1987-88-89) «El grupo 'Arte Nuevo' y el teatro español de posguerra», Estudios Románicos, 5, pp. 10651078.

Henríquez-Sanguineti, Carolina (2001) «Alfonso Sastre como portavoz de tendencias e inquietudes del siglo XX», Actas del XIV Congreso de AIH, 3, pp. 301-306.

Kristeva, Julia (1978) Semiótica, Madrid, Fundamentos, 1969.

Martínez Alfaro, Mํㅡㄹ Jesús (1996) «Intertextuality: Origins and Development of the Concept», Atlantis, 18, 1-2, junio-diciembre, pp. 268-285.

Rodríguez-Gago, Antonia (1987) «Beckett in Madrid (1955) and Barcelona (1956)», en Cohn, Ruby, Beckett: Waiting for Godot. A Casebook, Londres, Macmillan, p. 45. 
Sastre, Alfonso (1957) «Siete notas sobre Esperando a Godot», Primer Acto, 1, abril, pp. 46-52.

SAstre, Alfonso (1957) «El teatro de Alfonso Sastre visto por Alfonso Sastre», Primer Acto, 5, noviembre-diciembre, p. 7.

Sastre, Alfonso (1964) Cargamento de sueños, Prólogo Patético y Asalto nocturno, ed. Monleón, José, Madrid, Taurus (El Mirlo Blanco).

Sastre, Alfonso (1965) Anatomía del realismo, Barcelona, Seix Barral (2⿺ ed. ampliada, 1974).

Sastre, Alfonso (1975) Escuadra hacia la muerte. La mordaza, ed. Anderson, Farris, Madrid, Castalia.

Sastre, Alfonso (1979) «Introducción» a La sangre y la ceniza. Crónicas romanas, ed. Ruggeri Marchetti, Magda, Madrid, Cátedra.

Sastre, Alfonso (1992) «Prólogo». Teatro de vanguardia (Comedia sonámbula, Uranio 235, Cargamento de sueños), Hondarribia: Hiru.

Sastre, Alfonso (2009) La taberna fantástica. Tragedia fantástica de la gitana Celestina, ed. de Paco, Mariano, Madrid: Cátedra (7 ed.).

Shelley, Percy Bysshe (2003) Adonais, en The Major Works, Oxford, Oxford University Press (World's Classics), pp. 529-46.

Wilde, Oscar (1961) Oscar Wilde. Obras inmortales. Traducción de Alfonso y José Sastre, Madrid, Edaf, 1961.

Wilder, Thornton (2000) Our Town and Other Plays, Londres, Penguin, 1938. 
